\title{
Comparison of heat treatment response of semisolid metal processed alloys A356 and F357
}

\author{
H. Möller*1, G. Govender ${ }^{1}$, W. E. Stumpf ${ }^{2}$ and P. C. Pistorius ${ }^{3}$
}

The heat treatment response of semisolid metal high pressure die cast Al-7Si-Mg alloys A356 and F357 was studied and compared. It was found that the heat treatment behaviour of alloy F357 is influenced markedly by the stability of the Mg containing $\pi$ phase. This phase, which dissolves in alloy A356 during solution treatment, persists in F357 and decreases the amount of magnesium in solid solution. This is the likely origin of the decrease in the aging response of the F357 alloy. The tensile properties (yield strength and ultimate tensile strength) of the alloys correlate much better with the Mg concentration in solid solution than with the bulk Mg content of the alloys. The recently developed shortened T6 heat treatment cycles for rheocast A356 were tested on alloy F357. The optimum artificial aging treatment was determined to be $180^{\circ} \mathrm{C}$ for $4 \mathrm{~h}$, regardless of the prior natural aging period.

Keywords: Semisolid metal forming, Alloy A356, Alloy F357, Artificial aging, Iron rich intermetallics

\section{Introduction}

Semisolid metal (SSM) processing is an effective near net shape manufacturing method in which the metal is formed in the semisolid state. ${ }^{1,2}$ With conventional liquid high pressure die casting (HPDC), the turbulent die filling is often responsible for oxide entrapment, porosity and blistering problems during heat treatment. However, the laminar flow during the die fill for SSMHPDC avoids the problems of oxide and gas entrapment and also reduces the shrinkage problems with solidification. ${ }^{3}$ The conventional casting alloys A356 and F357 are probably the most popular alloys used for semisolid metal forming. This is due to their high fluidity and good 'castability'. ${ }^{4}$ The chemical composition limits of these two alloys, as well as that of alloy A357 (a Be containing variant of 357), are shown in Table $1 .{ }^{5}$ The main difference between alloy A356 and the 357 alloys is the magnesium content.

With regard to aging reactions, in $\mathrm{Al}-\mathrm{Mg}-\mathrm{Si}$ alloys containing an excess of silicon, the decomposition of the supersaturated solid solution (SSS) is believed to occur as follows ${ }^{6}$

$$
\begin{aligned}
& \mathrm{SSS} \rightarrow(\mathrm{Mg}+\mathrm{Si})_{\text {clusters }} / \mathrm{GP}(\mathrm{I})_{\text {spherical }} \\
& \rightarrow \beta^{\prime \prime} / \mathrm{GP}(\mathrm{II})_{\text {needles }} \rightarrow \beta_{\text {rods }}^{\prime}+\mathrm{Si}+\text { others } \\
& \rightarrow \beta_{\text {plates }}+\mathrm{Si}
\end{aligned}
$$

\footnotetext{
${ }^{1}$ Materials Science and Manufacturing, CSIR, Pretoria, South Africa ${ }^{2}$ Department of Materials Science and Metallurgical Engineering, University of Pretoria, Pretoria, South Africa

${ }^{3}$ Department of Materials Science and Engineering, Carnegie Mellon University, Pittsburgh, PA, USA

*Corresponding author, email hmoller@csir.co.za
}

where GP is Guinier-Preston zones, $\beta$ is equilibrium $\beta-\mathrm{Mg}_{2} \mathrm{Si}$, and $\beta^{\prime}$ and $\beta^{\prime \prime}$ are metastable precursors of $\beta-\mathrm{Mg}_{2} \mathrm{Si}$.

The natural aging response of these alloys is considered to be due to $(\mathrm{Mg}+\mathrm{Si})$ clusters and $\mathrm{GP}$ zones. ${ }^{6}$ The precipitation hardening which results from natural aging alone produces the T4 temper. Peak hardening with artificial aging results from the precipitation of the metastable and coherent $\beta^{\prime \prime}$. ${ }^{6}$ The difference in $\mathrm{Mg}$ content between alloy A356 and the 357 alloys should therefore have a significant effect on their precipitation hardening characteristics. A higher $\% \mathrm{Mg}$ should lead to a higher volume fraction of the second phase $\beta-\mathrm{Mg}_{2} \mathrm{Si}$, and most likely also of $\beta^{\prime}$ and $\beta^{\prime \prime}$. This in turn should result in alloy F357 having higher strength than A356.

The difference between alloys F357 and A357 is their beryllium content (Table 1). The addition of beryllium to this alloy system (alloy A357) leads to a change in the morphology of the iron rich intermetallics, which results in slightly better ductility. ${ }^{7}$ Alloy A357 is gradually being phased out in many applications due to the carcinogenic effects of beryllium, particularly at higher concentrations used during make-up of the alloy. The beryllium free alloy F357 is frequently incorrectly labelled as A357, especially in semisolid metal research. ${ }^{8,9}$

Taylor and co-workers ${ }^{10,11}$ have studied the influence of solution treatment on the changes to the relative proportions of iron containing intermetallic particles in these alloys. They showed that solution treatment causes a substantial transformation of the $\pi$ phase $\left(\mathrm{FeMg}_{3} \mathrm{Si}_{6} \mathrm{Al}_{8}\right)$ to the $\mathrm{Mg}$ free $\beta$-phase $\left(\mathrm{FeSiAl}_{5}\right)$ in low $\mathrm{Mg}$ alloys $(0 \cdot 3-0 \cdot 4 \%$ or A356). However, this 
transformation does not occur at higher $\mathrm{Mg}$ levels $(0 \cdot 6-$ $0 \cdot 7 \%$ or $\mathrm{F} 357$ ). The transformation of $\mathrm{Mg}$ containing $\pi$ to $\beta-\mathrm{FeSiAl}_{5}$ is accompanied by a release of $\mathrm{Mg}$ into the aluminium matrix, which should have an influence on the subsequent aging response of the alloy (equation (1)). Note that the two different $\beta$-phases will be referred to as $\beta-\mathrm{Mg}_{2} \mathrm{Si}$ and $\beta-\mathrm{FeSiAl}_{5}$ in this paper.

The aim of this work was firstly to study the influence of the magnesium content and intermetallic compounds ( $\pi$ and $\beta-\mathrm{FeSiAl}_{5}$ ) in both alloys (with similar $\% \mathrm{Fe}$ ) on the T6 tensile properties. Second, the suitability of previously developed optimised A356 heat treatment cycles $^{12-15}$ for the SSM-HPDC alloy F357 was also investigated.

\section{Experimental procedure}

The chemical composition of the different A356 samples that were studied previously is given in Table 2. Semisolid metal slurries of alloy F357 (chemical composition given in Table 2) were prepared using the CSIR rheocasting process. ${ }^{16}$ Plates $(4 \times 80 \times 100 \mathrm{~mm})$ were cast in steel moulds with a 50 ton high pressure die casting machine. The 'traditional' $\mathrm{T} 6$ heat treatment ${ }^{17}$ of solution treatment at $540^{\circ} \mathrm{C}$ for $6 \mathrm{~h}$, natural aging for $20 \mathrm{~h}$ and artificial aging at $170^{\circ} \mathrm{C}$ for $6 \mathrm{~h}$, was used to study the effect of $\mathrm{Mg}$ content of the alloys on the tensile properties. Thermo-Calc (a commercially available software package used to perform thermodynamic and phase diagram calculations for multicomponent systems of practical importance $)^{18}$ was used to investigate the possible effect of a variable $\mathrm{Mg}$ content on the equilibrium phases in the alloys, using the Al-DATA ver. 2 database. To study the applicability of the optimised heat treatments developed for SSM-HPDC A356 for alloy F357, solution heat treatments were performed at $540^{\circ} \mathrm{C}$ for 1 or $6 \mathrm{~h}$, followed by a water quench $\left(25^{\circ} \mathrm{C}\right)$. For the T6 temper, the samples were firstly naturally aged (NA) for either zero hours (artificial aging only) or $20 \mathrm{~h}$ before being artificially aged at $180^{\circ} \mathrm{C}$. All samples used for microscopy were etched in $0.5 \% \mathrm{HF}$ solution. The tensile properties of the differently heat treated samples were determined using an INSTRON 1342/H1314 with $25 \mathrm{kN}$ load cell capacity and an INSTRON Model 2620-602 extensometer with gauge length of $12.5 \mathrm{~mm}$. To determine the $0.2 \%$ proof stress, a stress rate of $10 \mathrm{MPa} \mathrm{s}^{-1}$ was used and for the ultimate tensile stress (UTS) determination a displacement rate of $10 \mathrm{~mm} \mathrm{~min}^{-1}$. These parameters were selected based on the American Society for Testing and Materials (ASTM) standard E8M-04. Tensile specimens (dimensions given in Fig. 1) were machined from the plates. A total of five tensile tests was used for each heat treatment condition.

Table 1 Chemical composition limits for alloys A356, F357 and $A 357^{5}$

\begin{tabular}{llllllllll}
\hline & & Si & Mg & Fe & Cu & Mn & Zn & Ti & Be \\
\hline A356 & Min. & 6.5 & 0.25 & $\ldots$ & $\ldots$ & $\ldots$ & $\ldots$ & $\ldots$ & $\ldots$ \\
& Max. & 7.5 & 0.45 & 0.20 & 0.20 & 0.10 & 0.10 & 0.20 & $\ldots$ \\
F357 & Min. & 6.5 & 0.40 & $\ldots$ & $\ldots$ & $\ldots$ & $\ldots$ & 0.10 & $\ldots$ \\
& Max. & 7.5 & 0.70 & 0.20 & 0.20 & 0.10 & 0.10 & 0.20 & $\ldots$ \\
A357 & Min. & 6.5 & 0.40 & $\ldots$ & $\ldots$ & $\ldots$ & $\ldots$ & 0.10 & 0.04 \\
& Max. & 7.5 & 0.70 & 0.20 & 0.20 & 0.10 & 0.10 & 0.20 & 0.07 \\
\hline
\end{tabular}

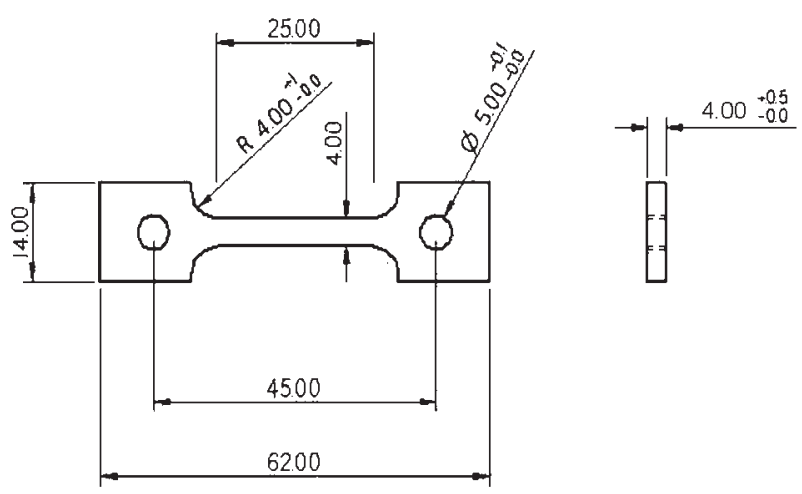

1 Dimensions of samples (in millimetres) used for tensile testing

\section{Results and discussion}

\section{Light microscopy}

Figure $2 a$ shows a light micrograph of the as cast F357. It is seen that the material has a globular primary grain structure and a fine eutectic, similar to the as cast microstructure of SSM-HPDC A356. ${ }^{12-15}$ Solution treatment at $540^{\circ} \mathrm{C}$ results in the eutectic structure changing to a globular type structure (Fig. $2 b$ and $c$ ). The size and shape of the silicon particles were modified with additions of strontium in the F357 used in this work (Table 2). Modified alloys are known to undergo fast spheroidisation of the silicon particles while complete spheroidisation is not achieved in unmodified alloys, even after long solution treatment times. ${ }^{5}$

\section{Scanning electron microscopy (SEM)}

Figure $3 a$ and $b$ shows scanning electron micrographs of SSM-HPDC A356 and F357 after solution treatment at $540^{\circ} \mathrm{C}$ for $6 \mathrm{~h}$. The needle-like phase that is found in both A356 and F357 has tentatively been identified by energy dispersive spectroscopy (EDS) (Fig. 4a) as likely to be $\beta-\mathrm{FeSiAl}_{5}$. The blocky intermetallic phase that was mainly found in F357 was identified with EDS (Fig. 4b) as likely to be the $\mathrm{Mg}$ containing $\pi$ phase $\left(\mathrm{FeMg}_{3} \mathrm{Si}_{6} \mathrm{Al}_{8}\right)$.

\section{Thermo-Calc equilibrium phase predictions}

The calculated phase equilibria (minor phases) for an Al alloy with a base composition of alloy F357 used in this study (Table 2), but with variable $\mathrm{Mg}$, are shown in Fig. 5. In this figure, the liquidus and solidus temperatures are indicated by arrows; 'pi' refers to the $\pi$ phase, 'beta' is $\beta-\mathrm{FeSiAl}_{5}$, and 'alpha' is an $\mathrm{Al}-\mathrm{Mn}-\mathrm{Fe}-\mathrm{Si}$ solid solution based on $\mathrm{Al}_{8} \mathrm{Fe}_{2} \mathrm{Si}$ (containing approximately equal amounts of $\mathrm{Mn}$ and $\mathrm{Fe}$ for the cases considered

Table 2 Chemical composition of alloys A356 and F357 used in this study, wt-\%

\begin{tabular}{lllllllll}
\hline Al & Si & Mg & Fe & Cu & Mn & Zn & $\mathrm{Ti}$ & $\mathrm{Sr}$ \\
\hline A356 & & & & & & & & \\
Balance & 7.10 & 0.25 & 0.14 & 0.01 & 0.01 & 0.01 & 0.08 & 0.04 \\
Balance & 7.21 & 0.28 & 0.13 & 0.01 & 0.01 & 0.01 & 0.12 & 0.04 \\
Balance & 7.15 & 0.31 & 0.13 & 0.01 & 0.01 & 0.02 & 0.09 & 0.02 \\
Balance & 7.14 & 0.34 & 0.14 & 0.01 & 0.01 & 0.03 & 0.08 & 0.03 \\
Balance & 7.14 & 0.36 & 0.10 & 0.01 & 0.01 & 0.01 & 0.07 & 0.02 \\
Balance & 7.08 & 0.40 & 0.10 & 0.01 & 0.01 & 0.01 & 0.08 & 0.02 \\
Balance & 6.81 & 0.45 & 0.12 & 0.01 & 0.01 & 0.01 & 0.09 & 0.02 \\
F357 & & & & & & & & \\
Balance & 7.01 & 0.62 & 0.10 & 0.01 & 0.01 & 0.01 & 0.13 & 0.02 \\
\hline
\end{tabular}




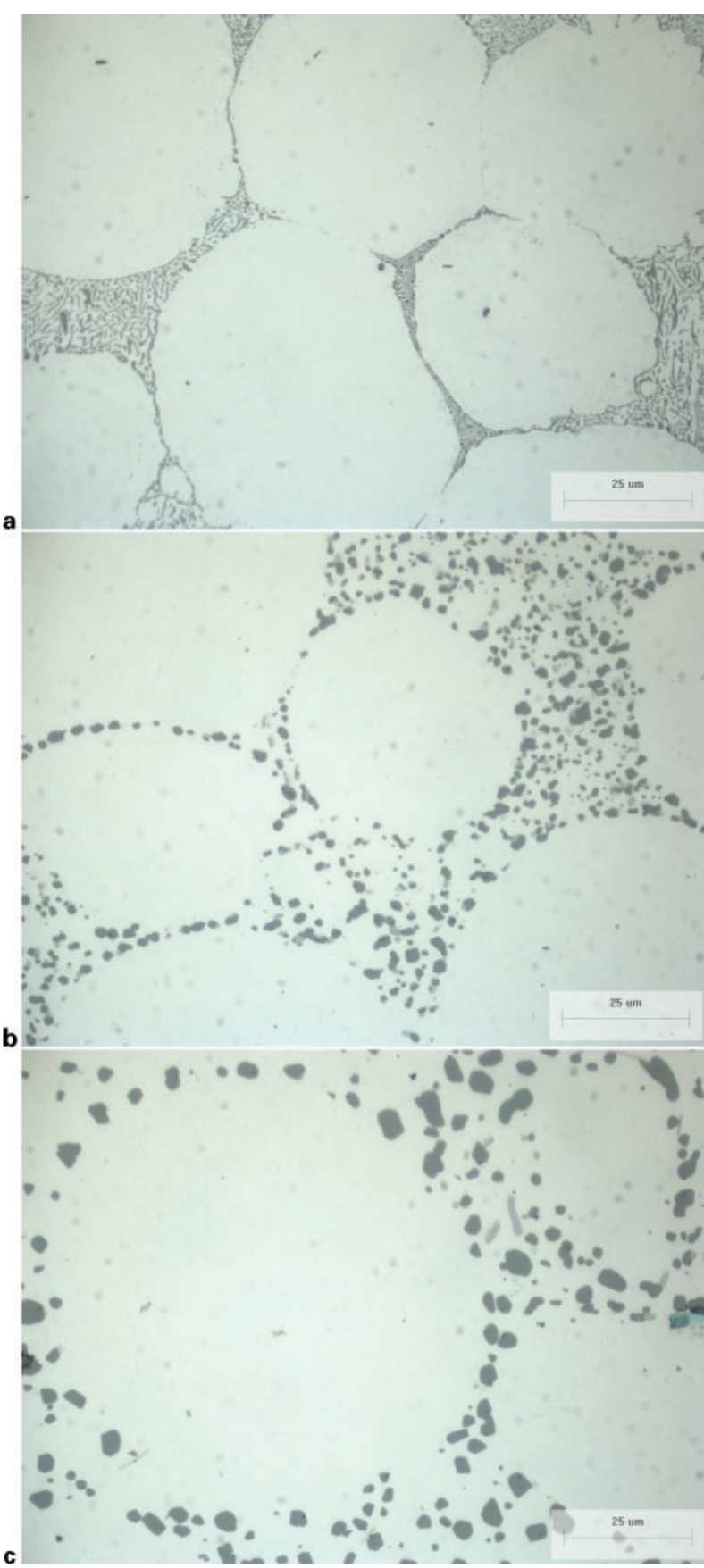

2 Light micrograph of $a$ as cast alloy F357, $b$ alloy F357 after solution treatment at $540^{\circ} \mathrm{C}$ for $1 \mathrm{~h}$ and $c$ alloy F357 after solution treatment at $540^{\circ} \mathrm{C}$ for $6 \mathrm{~h}$

here). In all cases the major phases were liquid, Al based fcc solid solution (the primary phase upon solidification), and Si (formed by eutectic solidification).

In the region of the solution temperature (just below the solidus) the effect is quite clear: higher $\mathrm{Mg}$ levels increase the stability range of $\pi$ to higher temperatures, and suppress $\beta$ - $\mathrm{FeSiAl}_{5}$ formation at high temperatures. A secondary effect is that the dissolution temperature of $\mathrm{Mg}_{2} \mathrm{Si}$ increases (and the equilibrium mass fraction of $\mathrm{Mg}_{2} \mathrm{Si}$ at low temperatures increases), as one would expect. The extension of the stability range of the $\pi$ phase to high temperatures is in line with the observation that it is not possible to remove $\pi$ by solution treatment in the high $\mathrm{Mg}$ alloys, as shown in Fig. 5 and also presented by Taylor and co-workers. ${ }^{10,11}$ According

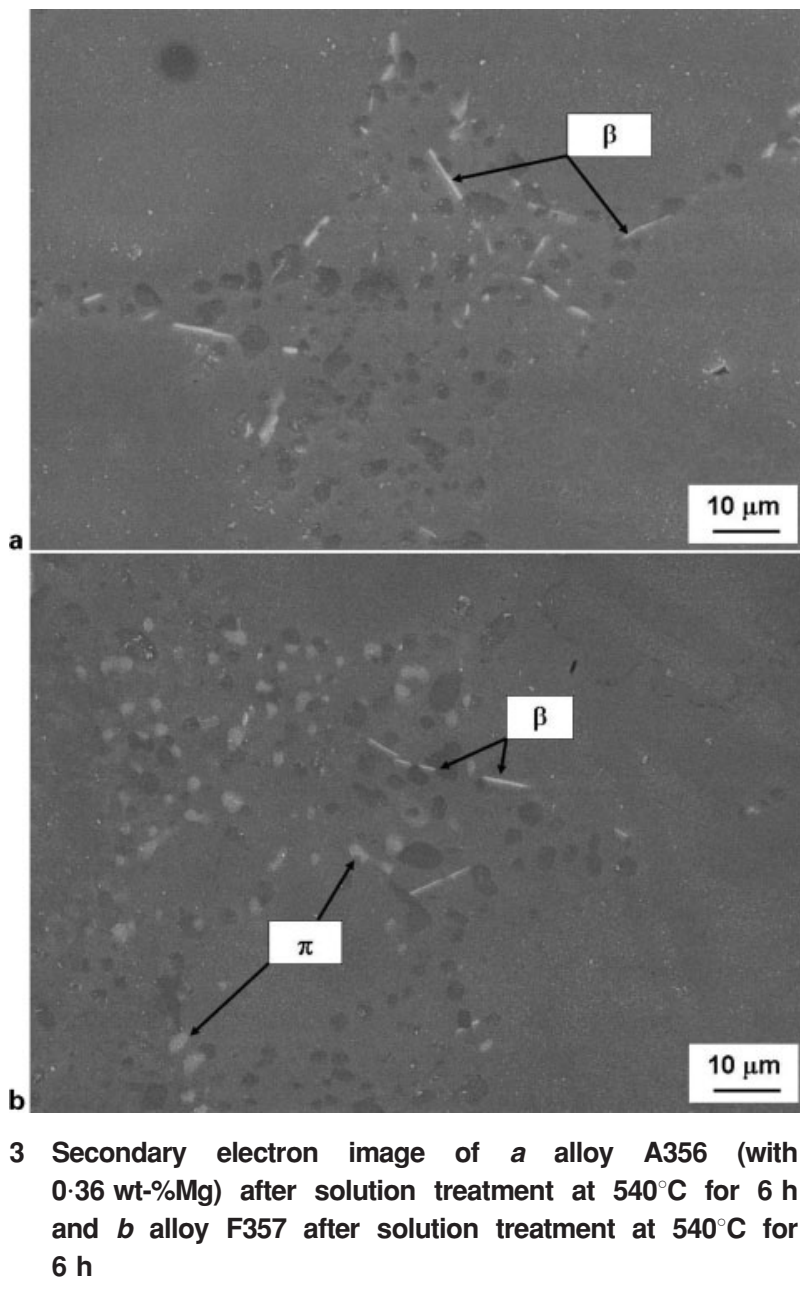

to the Thermo-Calc results, the dissolution temperature of $\pi$ increases linearly with the $\mathrm{Mg}$ content of the alloy, and reaches $540^{\circ} \mathrm{C}$ at a $\mathrm{Mg}$ content of $0.40 \%$. This means that $\pi$ phase cannot be fully removed by solution treatment at $540^{\circ} \mathrm{C}$ in alloys which contain more than $0 \cdot 4 \% \mathrm{Mg}$ (for the base composition considered here).

\section{Tensile properties}

The tensile properties of alloys A356 and F357 obtained using the traditional T6 heat treatment $\left(540^{\circ} \mathrm{C} / 6 \mathrm{~h}, 20 \mathrm{~h}\right.$ NA, $\left.170^{\circ} \mathrm{C} / 6 \mathrm{~h}\right)$ are compared in Fig. 6 . The tensile properties reported by other researchers ${ }^{8,17}$ for semisolid processed A356 and F357, heat treated using the traditional parameters, have also been included in Fig. 6 (Rosso and co-workers ${ }^{8}$ used a slightly different solution treatment of $535^{\circ} \mathrm{C}$ for $6 \mathrm{~h}$, but the traditional artificial aging treatment of $170^{\circ} \mathrm{C}$ for $6 \mathrm{~h}$ ). A lower increase in strength with bulk $\mathrm{Mg}$ concentration is observed for alloy F357 when compared to alloy A356. This is in line with the findings of Taylor and coworkers $^{11}$ who determined the matrix $\mathrm{Mg}$ content of A356 and F357 alloys (the Mg concentration in solid solution after solution treatment) by using electron probe microanalysis (EPMA). The actual Mg concentration in solid solution after solution treatment, as a function of the bulk Mg content of the alloys is shown in Fig. $7^{11}$ (for $\mathrm{Fe}$ contents of $0 \cdot 12 \mathrm{wt}-\%$ ). In the low $\mathrm{Mg}$ alloys (A356), it is seen that the final matrix $\mathrm{Mg}$ concentration equals the bulk $\mathrm{Mg}$ content of the alloy. This implies that, during solution treatment, all the as cast $\mathrm{Mg}_{2} \mathrm{Si}$ was dissolved, and that the $\pi$ phase was also 


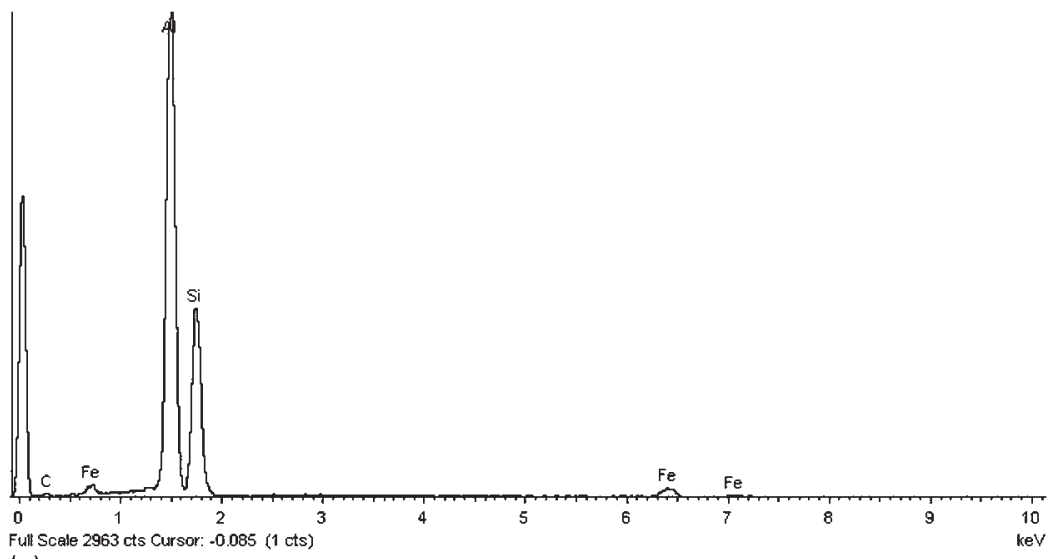

(a)

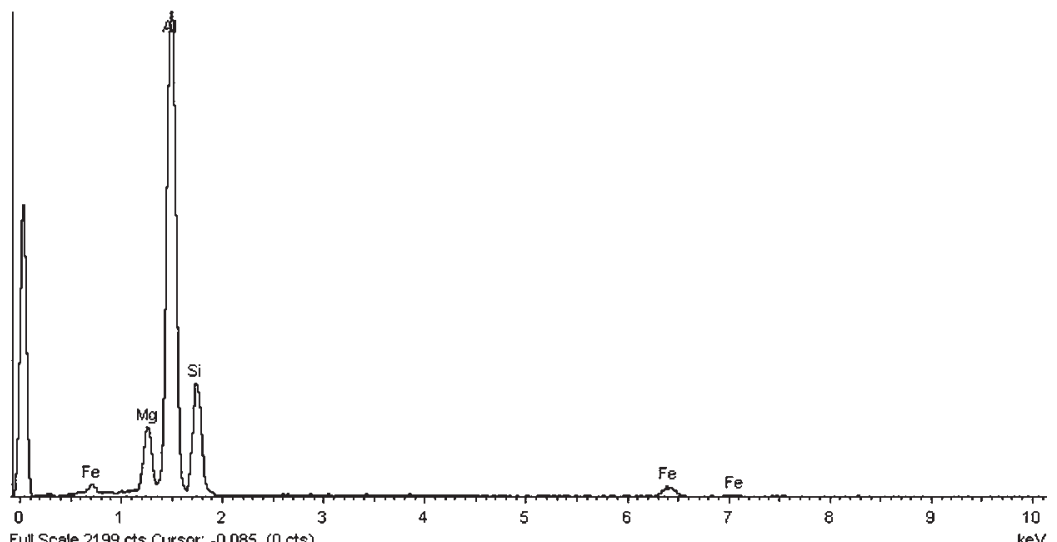

(b)

4 EDS results for $a \beta$-FeSiAl 5 particle (note absence of $\mathrm{Mg}$ peak) and $\boldsymbol{b} \pi$ particle (note presence of Mg peak)

dissolved. As the alloy $\mathrm{Mg}$ content increases, the matrix $\mathrm{Mg}$ levels do not reach the bulk values (Fig. 7). Since very little $\mathrm{Mg}_{2} \mathrm{Si}$ is expected to remain after the solution treatment (Fig. 5), this phenomenon is due to the increased stability of the $\pi$ phase as the alloy $\mathrm{Mg}$ content is increased (Fig. 5). In Fig. 7, deviation from full dissolution of $\mathrm{Mg}$ in the matrix occurs at approximately $0 \cdot 4 \% \mathrm{Mg}$, which (as discussed previously) is the predicted $\mathrm{Mg}$ content above which $\pi$ phase is impossible to remove completely during the solution treatment.

The data from Taylor and co-workers ${ }^{11}$ as plotted in Fig. 7 were used to estimate the actual Mg concentration in solid solution for the bulk compositions used in Fig. 6. The data of Fig. 6 were then redrawn as yield strength (YS) and ultimate tensile strength (UTS) as functions of $\mathrm{Mg}$ concentration in solid solution (rather than bulk $\mathrm{Mg}$ concentration) and the result is shown in Fig. 8. A linear correlation between strength and $\mathrm{Mg}$ concentration in solid solution can then be found. This result is significant in that it shows just how important it is to control the iron levels in these alloys in order to obtain optimal tensile properties, especially for alloy F357. The significance of iron is that it promotes formation of the $\pi$ phase (which contains both $\mathrm{Mg}$ and $\mathrm{Fe}$ ) and therefore removes the strengthening solute $\mathrm{Mg}$ from solid solution; as shown in Fig. $5, \pi$ phase persists during solution heat treatments in high $\mathrm{Mg}$ alloys, and $\pi$ phase (rather than $\beta$ ) is the main $\mathrm{Fe}$ containing phase in the high $\mathrm{Mg}$ alloys at solution treatment temperatures.

\section{Shorter heat treatment cycles}

It has been shown by the authors ${ }^{12-15}$ that for SSMHPDC alloy A356, shorter T6 heat treatments than the traditional heat treatment can be used to obtain similar properties. It is known that maximum hardness reaches a plateau after only $1 \mathrm{~h}$ at $180^{\circ} \mathrm{C}$ with no prior natural aging. Time to peak hardness is increased to $4 \mathrm{~h}$ in all naturally aged samples. Maximum yield strength and ultimate tensile strength can be achieved after $2 \mathrm{~h}$ at $180^{\circ} \mathrm{C}$ with no prior natural aging, and after $4 \mathrm{~h}$ at $180^{\circ} \mathrm{C}$ with prior natural aging. The applicability of the above mentioned statements to SSM-HPDC F357 was investigated and the results are shown in Table 3.

The tensile properties of alloy F357 samples that were not naturally aged before artificial aging at $180^{\circ} \mathrm{C}$ for different times are shown in Fig. 9. It is seen that, as with alloy A356, the ultimate tensile strength is not influenced much by artificial aging time between 1 and $4 \mathrm{~h}$. However, the yield strength is influenced significantly. With A356, maximum yield strength was reached after $2 \mathrm{~h}$ at $180^{\circ} \mathrm{C} .{ }^{15}$ Considering Fig. 9 , it seems that this time needs to be increased to $4 \mathrm{~h}$ for alloy F357.

Natural aging before artificial aging has an adverse influence on the subsequent artificial aging response. ${ }^{12-15}$ The tensile properties of alloy F357 samples that were naturally aged for $20 \mathrm{~h}$ before artificial aging at $180^{\circ} \mathrm{C}$ for different times are also shown in Fig. 9. In contrast to when no natural aging is allowed, the ultimate tensile strength increases more slowly when the alloy has been naturally aged. For the naturally aged material, maximum yield strength and 


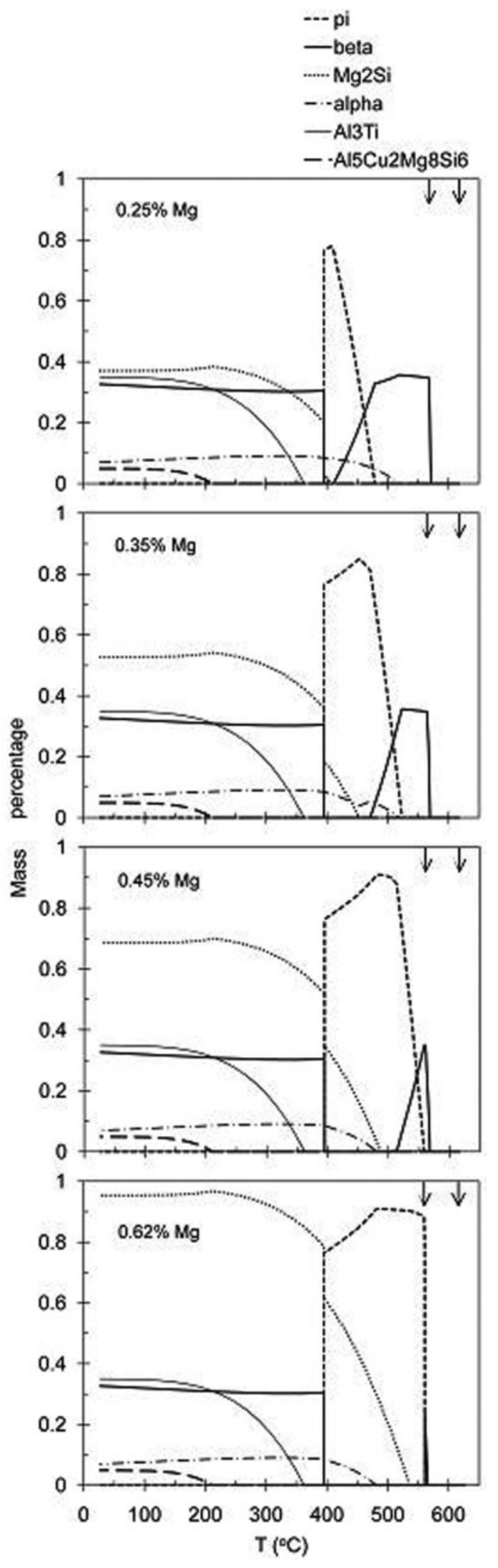

5 Calculated phase equilibria (minor phases) for Al alloy containing $\quad 7.01 \% \mathrm{Si}, \quad 0.10 \% \mathrm{Fe}, \quad 0.01 \% \mathrm{Cu}, \quad 0.01 \% \mathrm{Mn}$, $0.01 \% \mathrm{Zn}, 0.13 \% \mathrm{Ti}$ and variable $\mathrm{Mg}$

maximum ultimate tensile strength are both only reached after $4 \mathrm{~h}$ (as was also found for alloy A356). ${ }^{14}$ As shown in Fig. 9, after $4 \mathrm{~h}$ of artificial aging at $180^{\circ} \mathrm{C}$, the naturally aged alloy reached the same strength as the

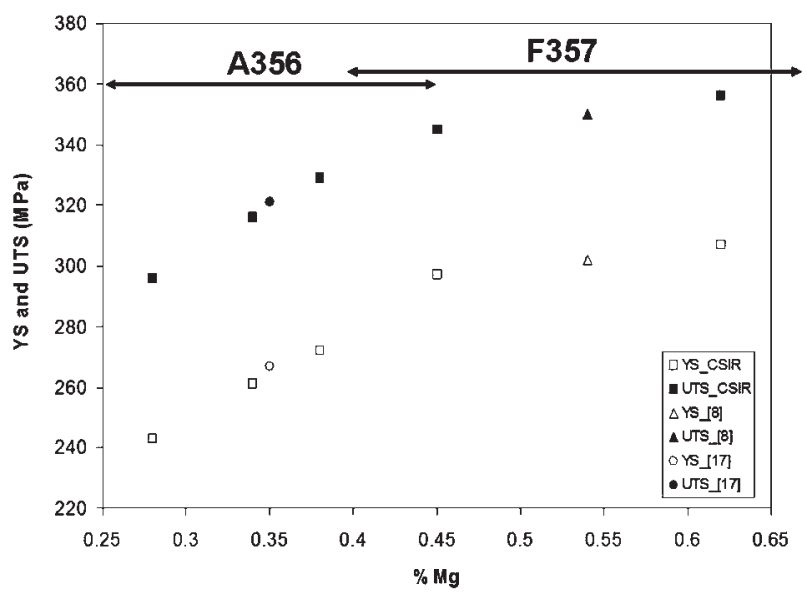

6 Yield strength (YS) and ultimate tensile strength (UTS) of SSM-HPDC A356-T6 and F357-T6 as a function of bulk Mg concentration of alloys. Heat treatment: 'Traditional': $540^{\circ} \mathrm{C} / 6 \mathrm{~h}, 20 \mathrm{~h}$ NA, $170^{\circ} \mathrm{C} / 6 \mathrm{~h}$

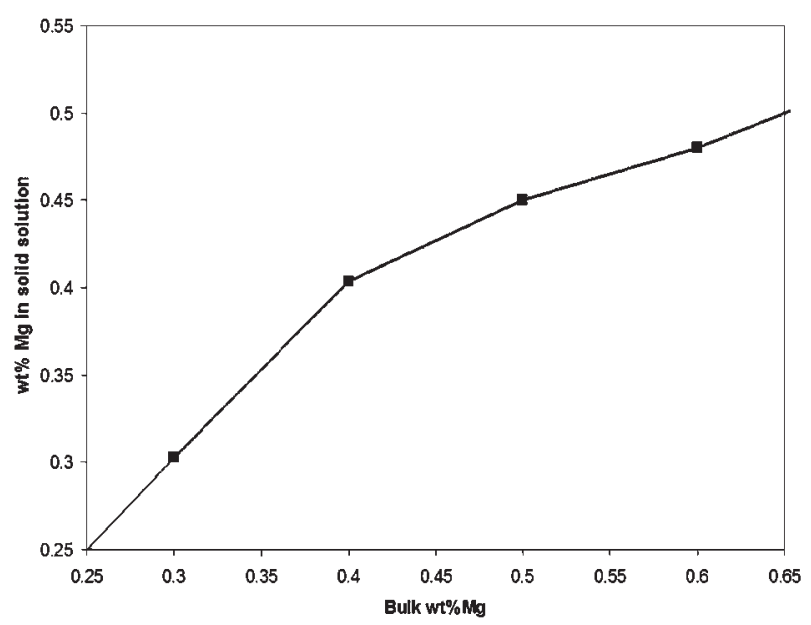

$7 \mathrm{Mg}$ concentration in solid solution (after solution treatment at $540^{\circ} \mathrm{C}$ ) as a function of bulk $\mathrm{Mg}$ concentration in $\mathrm{Al}-7 \mathrm{Si}-\mathrm{Mg}$ alloys ${ }^{11}$

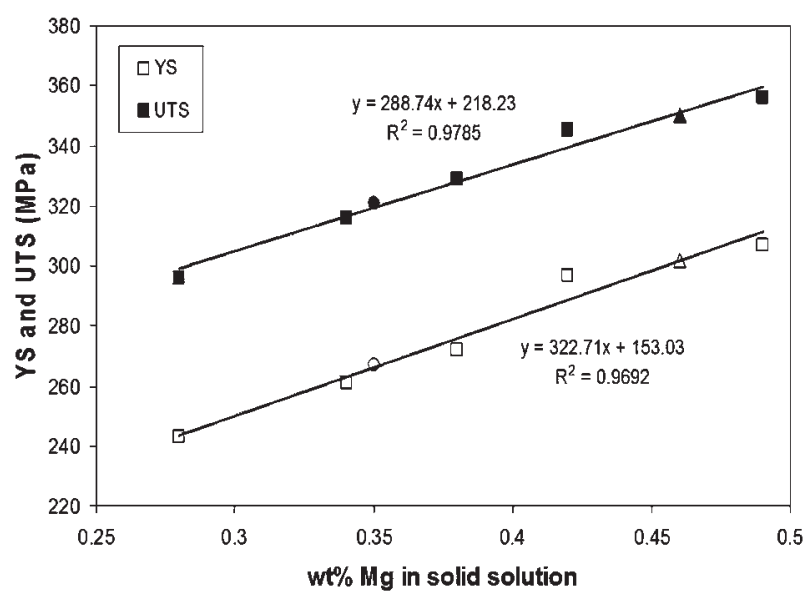

8 Yield strength (YS) and ultimate tensile strength (UTS) as a function of $\mathrm{Mg}$ concentration in solid solution before aging (same data points used as in Fig. 5)

alloy which was not naturally aged before artificial aging. The detailed effect of aging on work hardening (as reflected in the changed ratio of yield strength to 


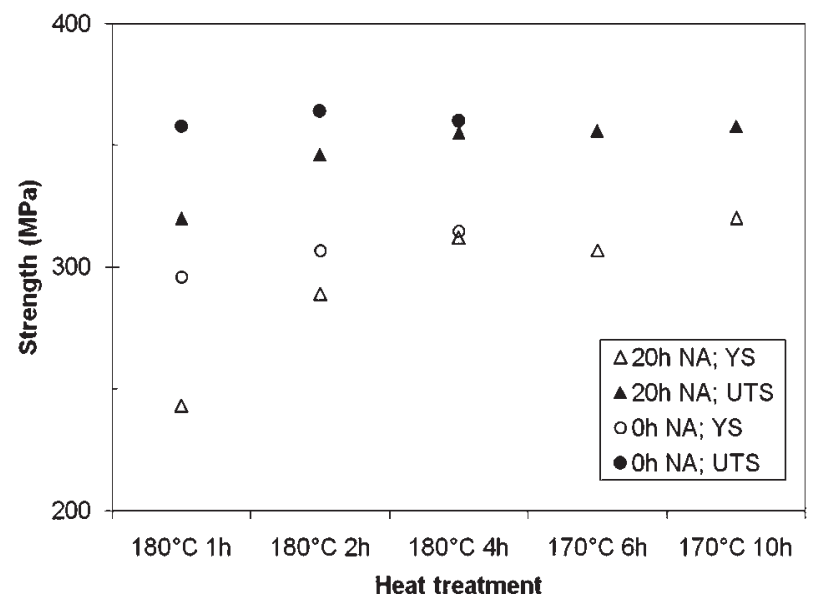

9 Yield strength (YS) and ultimate tensile strength (UTS) of alloy F357, with and without $20 \mathrm{~h}$ of prior natural aging (NA), after different artificial aging heat treatments

tensile strength) is not reported in detail here, but is the topic of ongoing work.

Figure 9 also compares the tensile properties of the shorter proposed heat treatment cycles with the traditional T6 heat treatment. It can be seen that similar properties can also be achieved for SSM-HPDC alloy F357 using these new proposed heat treatment cycles, with the advantage of time and energy savings.

The time to maximum hardness during artificial aging of SSM-HPDC A356 can be predicted by using Arrhenius type equations ${ }^{12}\left(t_{\mathrm{T} 6}=C \exp (Q / R T)\right.$ with $C$ the pre-exponential factor, $Q$ the apparent activation energy in $\mathrm{J} \mathrm{mol}^{-1}$ and $R$ the universal gas constant $=8.314 \mathrm{~J} \mathrm{~mol}^{-1} \mathrm{~K}^{-1}$ ). The equations that describe the time to reach maximum hardness $\left(t_{\mathrm{T} 6}\right)$ are given by equation (2) (with prior natural aging time) and equation (3) (for no natural aging time) ${ }^{12}$

$$
\begin{aligned}
& t_{\mathrm{T} 6}=2 \cdot 3 \times 10^{-15} \exp (163000 / R T) \\
& t_{\mathrm{T} 6}=4 \cdot 9 \times 10^{-16} \exp (163000 / R T)
\end{aligned}
$$

with $t_{\mathrm{T} 6}$ the time in seconds and $T$ the artificial aging temperature in $\mathrm{K}$.

By using equation (2), it can be shown that the traditional heat treatment $\left(540^{\circ} \mathrm{C} / 6 \mathrm{~h}, 20 \mathrm{~h} \mathrm{NA}, 170^{\circ} \mathrm{C} /\right.$ $6 \mathrm{~h})$ results in the alloy A356 being in the under aged condition. This conclusion is also supported by Badiali and co-workers. ${ }^{17}$ According to equation (2), artificial aging at $170^{\circ} \mathrm{C}$ for $10 \mathrm{~h}$ would be required to obtain the peak aged condition. Figure 9 finally compares the
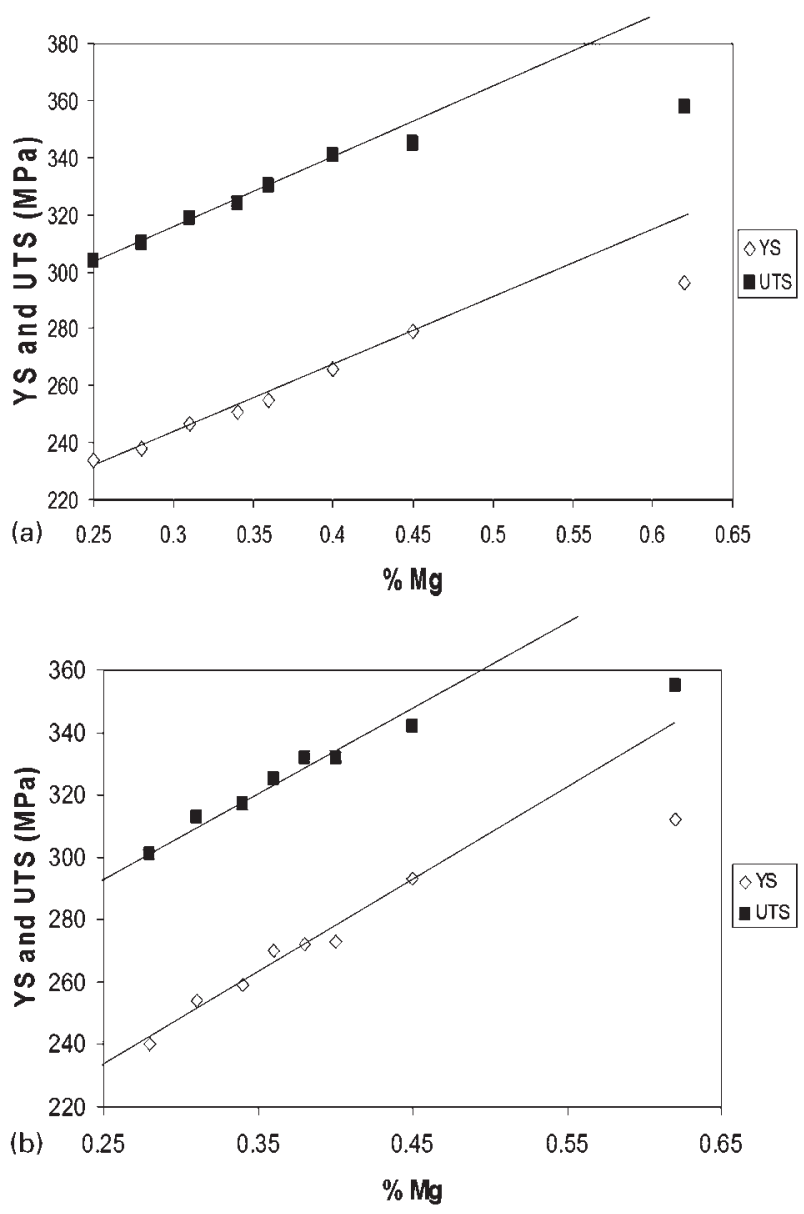

a solution treated at $540^{\circ} \mathrm{C}$ for $1 \mathrm{~h}$, water quenched $\left(25^{\circ} \mathrm{C}\right)$, natural aging for $0 \mathrm{~h}$, artificially aged at $180^{\circ} \mathrm{C}$ for $1 \mathrm{~h} ; b$ solution treated at $540^{\circ} \mathrm{C}$ for $1 \mathrm{~h}$, water quenched $\left(25^{\circ} \mathrm{C}\right)$, natural aging for $20 \mathrm{~h}$, artificially aged at $180^{\circ} \mathrm{C}$ for $4 \mathrm{~h}$

10 Yield strength (YS) and ultimate tensile strength (UTS) of SSM-HPDC A356-T6 and F357-T6 as a function of the bulk Mg concentration of the alloys.

tensile properties of SSM-HPDC alloy F357 that was aged at $170^{\circ} \mathrm{C}$ for either 6 or $10 \mathrm{~h}$. It can be seen that better properties (particularly yield strength) are indeed obtained with the $10 \mathrm{~h}$ heat treatment. This implies that the Arrhenius type equations that were derived originally for SSM-HPDC A356 can be used successfully for F357 too.

The influence of $\mathrm{Mg}$ concentration on the currently studied A356 and F357 heat treatments are shown in Fig. $10 a$ and $b$. The results support the proposed negative effect of $\pi$ phase stability at high $\mathrm{Mg}$ contents.

Table 3 Yield strength (YS), ultimate tensile strength (UTS) and \% elongation of heat treated F357 samples*

\begin{tabular}{llll}
\hline Heat treatment & YS, MPa & UTS, MPa & \% elongation \\
\hline $540^{\circ} \mathrm{C} / 6 \mathrm{~h}, 20 \mathrm{~h} \mathrm{NA}, 170^{\circ} \mathrm{C} / 6 \mathrm{~h}$ & $307(5 \cdot 7)$ & $356(4 \cdot 8)$ & $6 \cdot 1(1 \cdot 5)$ \\
$540^{\circ} \mathrm{C} / 6 \mathrm{~h}, 20 \mathrm{~h} \mathrm{NA}, 170^{\circ} \mathrm{C} / 10 \mathrm{~h}$ & $320(4 \cdot 5)$ & $358(3 \cdot 1)$ & $5 \cdot 8(1 \cdot 2)$ \\
$540^{\circ} \mathrm{C} / 1 \mathrm{~h}, 0 \mathrm{~h} \mathrm{NA}, 180^{\circ} \mathrm{C} / 1 \mathrm{~h}$ & $296(2 \cdot 9)$ & $358(3 \cdot 7)$ & $7 \cdot 4(0 \cdot 7)$ \\
$540^{\circ} \mathrm{C} / 1 \mathrm{~h}, 0 \mathrm{~h} \mathrm{NA}, 180^{\circ} \mathrm{C} / 2 \mathrm{~h}$ & $307(3 \cdot 1)$ & $364(2 \cdot 5)$ & $9 \cdot 6(2 \cdot 4)$ \\
$540^{\circ} \mathrm{C} / 1 \mathrm{~h}, 0 \mathrm{~h} \mathrm{NA}, 180^{\circ} \mathrm{C} / 4 \mathrm{~h}$ & $315(5 \cdot 2)$ & $360(5 \cdot 0)$ & $5 \cdot 7(1 \cdot 1)$ \\
$540^{\circ} \mathrm{C} / 1 \mathrm{~h}, 20 \mathrm{~h} \mathrm{NA}, 180^{\circ} \mathrm{C} / 1 \mathrm{~h}$ & $243(6 \cdot 2)$ & $320(7 \cdot 9)$ & $9 \cdot 5(2 \cdot 6)$ \\
$540^{\circ} \mathrm{C} / 1 \mathrm{~h}, 20 \mathrm{~h} \mathrm{NA}, 180^{\circ} \mathrm{C} / 2 \mathrm{~h}$ & $289(10 \cdot 7)$ & $346(4 \cdot 5)$ & $8 \cdot 0(2 \cdot 4)$ \\
$540^{\circ} \mathrm{C} / 1 \mathrm{~h}, 20 \mathrm{~h} \mathrm{NA}, 180^{\circ} \mathrm{C} / 4 \mathrm{~h}$ & $312(4 \cdot 1)$ & $355(3 \cdot 9)$ & $6 \cdot 0(1 \cdot 3)$ \\
$540^{\circ} \mathrm{C} / 6 \mathrm{~h}, 20 \mathrm{~h} \mathrm{NA}, 180^{\circ} \mathrm{C} / 4 \mathrm{~h}$ & $317(4 \cdot 9)$ & $5 \cdot 6(1 \cdot 4)$ \\
\hline
\end{tabular}

*The standard deviation from five values for tensile properties is also indicated in brackets. 


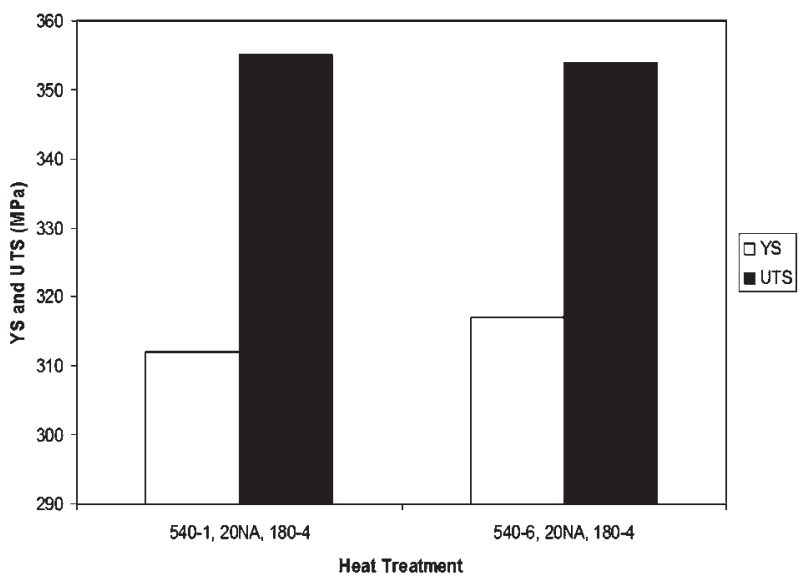

11 Tensile properties of SSM-HPDC F357-T6 for solution treatment times of 1 and $6 \mathrm{~h}$ at $540^{\circ} \mathrm{C}$, in both cases followed by $20 \mathrm{~h}$ of natural aging, and then artificial aging at $180^{\circ} \mathrm{C}$ for $4 \mathrm{~h}$

As discussed earlier, equilibrium calculations predict that $\pi$ phase cannot be removed by solution treatment if the alloys have $\mathrm{Mg}$ contents greater than $0 \cdot 4 \%$, with the result that only part of the $\mathrm{Mg}$ content is available for strengthening. This causes the strength of alloys with more than $0 \cdot 4 \% \mathrm{Mg}$ to be lower than expected: linear extrapolations of the strength of lower Mg A356 alloys to the actual F357 Mg concentrations used in this study predict higher strengths than actually achieved.

The influence of solution treatment time at $540^{\circ} \mathrm{C}$ on the dissolution of strengthening solutes was also studied for the F357-T6 temper. Figure 11 compares the yield strengths and ultimate tensile strengths of F357 artificially aged at $180^{\circ} \mathrm{C}$ for $4 \mathrm{~h}$ (with $20 \mathrm{~h}$ prior natural aging). No significant differences are observed for the 1 and $6 \mathrm{~h}$ solution treated material, implying that all as cast $\mathrm{Mg}_{2} \mathrm{Si}$ is dissolved within 1 hour and that the $\pi$ phase remains stable even after $6 \mathrm{~h}$ solution treatment time.

The \% elongation of SSM-HPDC F357-T6 (Table 3) is lower than was observed for A356-T6 heat treated using the same cycles. ${ }^{13-15}$ This is due, in part, to the higher strength of F357 compared with A356. Given the similarity of the F357 and A356, a trade-off between strength and ductility is expected. The pinning of dislocations, which induces strengthening, also causes local strain/stress concentrations which degrades the deformation capability. It is also known that the presence of the $\pi$ phase in alloy F357 causes a reduction in ductility. ${ }^{10}$

\section{Conclusions}

The conclusions of this study are as follows.

1. Higher $\mathrm{Mg}$ levels in $\mathrm{Al}-7 \mathrm{Si}-\mathrm{Mg}$ alloys increase the stability range of the $\mathrm{Mg}$ containing $\pi$ phase to higher temperatures, and suppress the $\mathrm{Mg}$ free $\beta$-FeSiAl $1_{5}$ phase at high temperatures

2. The stability of the $\pi$ phase in alloy F357 causes a reduction in the amount of magnesium in solid solution. This has a detrimental effect on the aging behaviour of this alloy compared to alloy A356.

3. Shorter T6 heat treatment cycles than the 'traditional' cycle can be used to obtain similar tensile properties in both alloys A356 and F357.

4. The optimum artificial aging treatment for SSMHPDC alloy $\mathrm{F} 357$ is $180^{\circ} \mathrm{C}$ for $4 \mathrm{~h}$, regardless of the prior natural aging period.

\section{Acknowledgements}

The contributions of D. Wilkins (SSM-HPDC) and C. McDuling, A. Grobler (tensile testing) are gratefully acknowledged, as well as financial support from the Department of Science and Technology (DST) in South Africa.

\section{References}

1. M. C. Flemings and R. A. Martinez: Solid State Phenom., 2006, 116-117, 1-8.

2. H. V. Atkinson: Prog. Mater. Sci., 2005, 50, 341-412.

3. W. L. Winterbottom: Metall. Sci. Technol., 2000, 18, 510.

4. D. Liu, H. V. Atkinson, P. Kapranos, W. Jirattiticharoean and H. Jones: Mater. Sci. Eng. A, 2003, A361, 213-224.

5. 'ASM specialty handbook: aluminium and aluminium alloys', 315-316, 718-720; 1993, Materials Park, OH, ASM International.

6. A. K. Gupta, D. J. Lloyd and S. A. Court: Mater. Sci. Eng. A, 2001, A301, 140-146.

7. C. Y. Yang, S. L. Lee, C. K. Lee and J. C. Lin: Mater. Chem. Phys, 2005, 93, 412-419.

8. M. Rosso, E. Romano, P. Giordano and G. L. Chiarmetta: Proc. 7 th Int. Conf. on 'Advanced semi-solid processing of alloys and composites', Tsukuba, Japan, September 2002, Japan Society for Technology of Plasticity, 151-156.

9. A. Forn, M. T. Baile, E. Martin, J. Goni and I. Sarries: Solid State Phenom., 2006, 116-117, 181-184.

10. J. A. Taylor, D. H. StJohn, L. H. Zheng, G. A. Edwards, J. Barresi and M. J. Couper: Aluminum Trans., 2001, 4-5, 95-110.

11. J. A. Taylor, D. H. StJohn and M. J. Couper: Aluminum Trans., 2001, 4-5, 111-124.

12. H. Möller, G. Govender and W. E. Stumpf: Open Mater. Sci. J., 2008, 2, 6-10.

13. H. Möller, G. Govender and W. E. Stumpf: Open Mater. Sci. J., 2008, 2, 11-18.

14. H. Möller, G. Govender and W. E. Stumpf: Int. J. Cast Met. Res., 2007, 20, 340-346.

15. H. Möller, G. Govender and W. E. Stumpf: Solid State Phenom., 2008, 141-143, 737-742

16. L. Ivanchev, D. Wilkins and G. Govender: Proc. 8th Int. Conf. on 'Semi-solid processing of alloys and composites', Limassol, Cyprus, September 2004, University of Cyprus, Paper 152.

17. M. Badiali, C. J. Davidson, J. R. Griffiths and A. Zanada: Proc. 6th Int. Conf. on 'Semi-solid processing of alloys and composites', Turin, Italy, September 2000, Edimet, 349-354.

18. J. O. Andersson, T. Helander, L. Höglund, P. F. Shi and B. Sundman: Calphad, 2002, 26, 273-312. 